\title{
Cellular Lipid Metabolism and the Role of Lipids in Progressive Renal Disease
}

\author{
Christine K. Abrass \\ Department of Medicine, University of Washington School of Medicine, Seattle, Wash., USA
}

\section{Key Words}

Dyslipidemia · Mesangial cells · Cholesterol · Chronic kidney disease, lipid metabolism • Glomerulosclerosis • Lipids

\begin{abstract}
Dyslipidemia contributes to the rate of progression of atherosclerosis and chronic kidney disease. Also, chronic kidney disease leads to the development of secondary abnormalities in lipid metabolism that contribute to increased cardiovascular morbidity and mortality. This review presents the mechanisms that underlie this risk. The mechanisms of normal cellular lipid metabolism and the abnormalities that develop in association with inflammation are reviewed. There is a special emphasis on foam cells in the kidney and on lipid-mediated changes in intrinsic kidney cells that lead to glomerulosclerosis and interstitial fibrosis. Correlates to studies performed in whole animals and humans are included.
\end{abstract} Copyright $\odot 2004$ S. Karger AG, Basel

\section{Introduction}

There is growing evidence of a pathogenic link between atherosclerosis and progressive kidney disease which in part accounts for the accelerated cardiovascular mortality in patients with chronic kidney disease [1-3]. Moreover, understanding the pathogenesis of vessel injury in atherosclerosis has provided insights into mechanisms that lead to kidney injury, as hyperlipidemia accelerates the rate of glomerulosclerosis, and reductions in lipid levels reverse this effect [4-7]. In blood vessel walls that become atherosclerotic, circulating lipids bind to and become trapped by extracellular matrix molecules [8], where they undergo oxidation [9]. This process is enhanced in the face of elevated levels of plasma lipids. Macrophages phagocytose oxidized lipids and undergo a transition to foam cells. Macrophage-derived foam cells release cytokines that recruit more macrophages to the lesion and influence lipid deposition, endothelial cell function, and vascular smooth muscle cell (VSMC) proliferation [10]. Eventually, VSMC also become foam cells. Intracellular accumulation of both cholesterol and triglycerides can alter VSMC responses to inflammatory stimuli and lead to extracellular matrix accumulation [11, 12]. Glomerular cells mimic some of these characteristics of cells in the atherosclerotic vessel wall [13]; therefore, similar pathogenic mechanisms may contribute to the progression of atherosclerosis and chronic kidney disease.

\section{Cellular Metabolism of Lipids}

The contribution of systemic fat storage and metabolism to atherosclerosis has been extensively reviewed [1416]. Lipid uptake and content at the cellular level in tis-

\begin{tabular}{ll}
\hline KARGER & (c) 2004 S. Karger AG, Basel \\
Fax +4161306 1234 & 0250-8095/04/0241-0046\$21.00/0 \\
$\begin{array}{l}\text { E-Mail karger@karger.ch } \\
\text { www.karger.com }\end{array}$ & $\begin{array}{l}\text { Accessible online at: } \\
\text { www.karger.com/ajn }\end{array}$
\end{tabular}

Christine K. Abrass, MD

VAPSHCS, 1660 S. Columbian Way

Seattle, WA 98108 (USA)

Tel. +1 206764 2002, Fax +1 2067642022

E-Mail cabrass@u.washington.edu 
sues that do not participate in systemic fat metabolism and storage are critical to cell function and can become disordered in disease. Cellular lipids play important roles in the synthesis of plasma membranes, in the membranes of organelles, and in signal transduction cascades that direct cell function. In order to meet these critical needs, uptake, synthesis, metabolism, and disposal of lipids by all cells are tightly regulated. Intracellular lipid synthesis can be stimulated by a variety of factors that activate sterol regulatory element binding proteins (SREBP). SREBP are leucine zipper transcription factors that reside in the membrane and, when cleaved, translocate to the nucleus, where they regulate the entire program of cholesterol (primarily SREBP-2) and fatty acid synthesis (primarily SREBP-1) [17]. Increased expression of these factors leads to increased cholesterol and fatty acid synthesis and high triglyceride and cholesterol contents. When the intracellular lipid content rises, SREBP transcription is suppressed which tends to restore lipid levels to normal. One of the key enzymes in the cholesterol synthetic pathway is hydroxymethylglutaryl coenzyme A reductase (HMG CoA R). When the intracellular levels of cholesterol are increased, the activity of this enzyme is decreased [18] which serves to prevent toxicity from progressive intracellular accumulation of cholesterol. Conversely, when intracellular levels of cholesterol fall, a protease is activated that cleaves SREBP from the membrane which serves to restore intracellular cholesterol by increasing synthesis and uptake through increased expression of low-density lipoprotein (LDL) receptors [19].

The intracellular lipid content is also influenced by the rate of uptake of lipids from the circulation. Cholesteryl ester rich LDL is taken up by the LDL receptor which in turn is normally downregulated, when the intracellular lipid levels rise [19]. This negative feedback regulation serves to maintain the intracellular cholesterol content relatively constant. Modified LDL, including oxidized LDL, is taken up by scavenger receptors (SR), including SR-A1 and CD36 (SR-BII) [20]. Acetylated and oxidized LDL are endocytosed following binding to SR-A1. The cholesteryl ester is hydrolyzed in lysosomes to produce free cholesterol which can be toxic to cells, when the levels are elevated. Unlike LDL receptors, the SR-A expression is not regulated by the intracellular cholesterol content $[11,2122]$. CD36 has a high affinity for LDL that has been minimally oxidized by myeloperoxidase which is enhanced in inflammatory states and diabetes [10]. CD36 expression is highly regulated. It is upregulated by oxidized LDL and cellular cholesterol which can lead to progressive lipid accumulation [22]. It is increased by ligands for peroxisome proliferator activated receptor gamma (PPAR- $\gamma$ ), including oxidized LDL, prostaglandin E, and synthetic agonists (e.g., thioglitazones). Transforming growth factor beta downregulates CD36 by phosphorylation and inactivation of PPAR- $\gamma$ [23].

Lipoprotein lipase hydrolyzes triglycerides in chylomicrons and very low density lipoprotein (VLDL) which controls plasma levels and reduces cellular uptake. When triglyceride levels are high, VLDL can contain large amounts of apolipoprotein $\mathrm{E}$ which induces a conformational change that is associated with unregulated uptake by SR [24]. Elevated triglyceride levels can also be associated with formation of small dense LDL particles, that are cleared slowly, which renders them more susceptible to oxidation and subsequent uptake by SR.

SR-B1 binds high-density lipoprotein (HDL), and it influences lipid uptake and cholesterol efflux. Cholesterol efflux is an important contributor to net cholesterol accumulation. Cholesterol efflux can occur passively through SR-B1 or actively via the adenosine triphosphate binding cassette A-1 (ABCA1) [25]. Cholesterol and triglyceride efflux are regulated by members of the PPAR family, including alpha,gamma, and delta, through their effects on ABCA1 activity [26, 27].

HDL influences the net cellular accumulation of lipid through a number of mechanisms. As a lipid-poor lipoprotein, it serves as an efficient acceptor for cholesterol and phospholipids that are transported across cells by the ABCA1 transporter, thereby enhancing cholesterol efflux. HDL stimulates increased expression of PPAR- $\gamma$ mRNA and protein and leads to PPAR- $\gamma$ phosphorylation which reduces the intracellular lipid accumulation by increasing ABCA1 [28]. HDL also blocks the normal increase in CD36 that accompanies ligation and phosphorylation of PPAR- $\gamma$, thereby decreasing the uptake of oxidized LDL via CD36 [28]. HDL reduces the adverse consequences of lipids by reducing oxidation of LDL and inhibiting cytokine-induced expression of adhesion molecules on endothelial cells.

Under normal circumstances, the pathways for cholesterol synthesis, uptake, and efflux are balanced to maintain stable intracellular lipid levels. In inflammatory states, lipids that are deposited in tissues by binding to extracellular matrix proteins become oxidized. Inflammatory cytokines and growth factors enhance the expression of influx pathways, particularly SR-A and CD36, inhibit efflux pathways, and may enhance synthesis, leading to significant intracellular lipid accumulation and foam cell formation. 


\section{Inflammation and Foam Cell Formation}

In order for foam cells to form, there must be net lipid accumulation. This can occur when regulatory mechanisms that maintain intracellular homeostasis become dysregulated. Inflammatory cytokines play an important role in mediating this dysregulation. Inflammatory cytokines block the downregulation of LDL receptors and HMG CoA $\mathrm{R}$ that normally occurs in response to increases in intracellular cholesterol [18]. SR determine cellular uptake of oxidized lipids which are particularly potent stimuli of release of inflammatory cytokines from macrophages. In turn, when monocyte chemoattractant protein 1 is released by monocytes that are exposed to oxidized LDL, increased expression of SR-BII/CD36 further enhances the uptake of oxidized LDL [29]. In this way, accumulation of oxidized lipids within the vessel wall can accelerate vessel injury. When CD36 is mutated, LDL does not accumulate, and foam cells do not form [30]. Furthermore, atherosclerosis-prone animals are protected from atherosclerosis when CD36 is absent [31]. These data demonstrate that CD36 plays a critical role in the pathogenesis of atherosclerosis. CD36 is also expressed on endothelial and smooth muscle cells; thus, its stimulation will alter the behavior of intrinsic vascular cells. CD36 is defective in spontaneously hypertensive rats, where it is thought to play a role in the hypertension, glucose intolerance, and defective adipocyte transport of long-chain fatty acids that are typical of that model $[32,33]$.

Work in atherosclerosis has focused on the adverse effects of oxidized LDL and its accumulation in foam cells that is primarily dependent upon CD36 activity [22]. Recent studies indicate that intracellular accumulation of triglyceride might also account for some of the abnormalities in the function of lipid-laden cells. In models of type 1 diabetes, SREBP-1 is increased in kidney cortex, resulting in upregulation of enzymes responsible for fatty acid synthesis and, as a consequence, a high renal triglyceride content. In these studies, upregulation of SREBP-1 was attributed to hyperglycemia per se and could be reversed by treatment with insulin [17]. When the SREBP-1 activity was inhibited, there was less mesangial matrix expansion and less glomerulosclerosis which implies that lipids contribute to the development of diabetic nephropathy. Animals that have normal serum lipid levels, but overexpress SREBP-1, have elevated renal triglyceride levels, increased expression of transforming growth factor beta and vascular endothelial growth factor, increased mesangial matrix expansion, and accumulation of collagen IV and fibronectin, proteinuria, and glomerulosclerosis [17].
These findings indicate that increased intracellular accumulation of triglycerides may play a central role in mediating the development of diabetic nephropathy. In nephritic syndrome, additional evidence implicates triglycerides in renal injury [34]. Elevated VLDL is associated with a reduction in lipoprotein lipase, and the VLDL particle shows defective binding to cells which leads to a decreased clearance. The abnormal VLDL particle also mediates inflammatory responses that lead to mesangial sclerosis [35]. As triglycerides play a key role in signal transduction cascades, metabolism and pathogenic significance of the cellular content of triglycerides deserve further study.

Foam cells are readily recognized in tissues by their increased staining with oil red O. It is widely accepted that they are the consequence of the presence of inflammatory cytokines and elevated concentrations of lipids, particularly oxidized LDL. Considerable evidence shows that once converted into foam cells, macrophages release cytokines, change their secretion of matrix metalloproteinases, and have other effects on the lesion in the vessel wall [36-38]. Although lipid can also accumulate in VSMC, which contribute to atherosclerotic lesions, functional consequences to the VSMC of lipid loading have not been reported. Also, recently, the lipid content of foam cells has been examined and surprisingly has shown that the majority of accumulated lipid is triglyceride [21, 39]. Although previously triglycerides were not thought to be pathogenic, their role as signal transduction molecules, the importance of the PPAR system in cholesterol efflux and particularly triglyceride turnover, and the relationship of dyslipidemia to insulin resistance have all indicated that knowledge of the triglyceride metabolism is important to understanding lipid-mediated injury.

\section{Lipids and Kidney Cells}

The significance of foam cells in the kidney and their relationship to progressive disease are subject of intense interest [40]. Zager and his colleagues have elucidated the details of alterations in intracellular lipids that occur in proximal tubular cells following ischemic injury [41-43]. Both free cholesterol and cholesteryl ester levels rise which in part is due to increased HMG CoA R driven cholesterol synthesis and increased cholesterol traffic to rafts and caveolar structures [43]. When cholesterol accumulation is prevented by treatment with $\mathrm{HMG}$ CoA R inhibitors, the cytoprotection from recurrent ischemia that normally develops in cells that survive is lost. These 


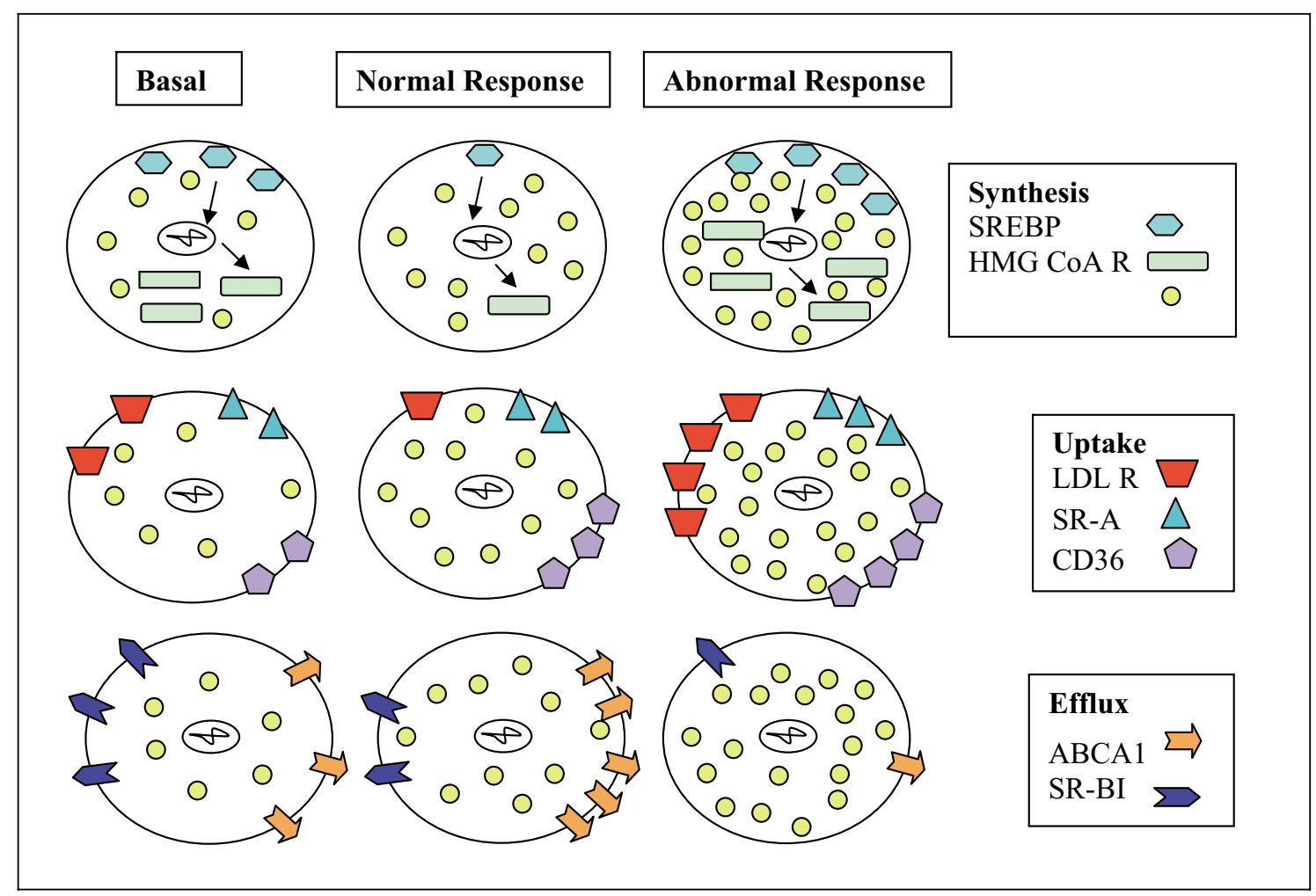

Fig. 1. Mesangial cell lipid metabolism: normal and abnormal responses to lipid loading.

data argue that in the short term, lipid accumulation in response to injury has a protective effect. This phenomenon was not restricted to ischemic injury, as Johnson et al. [44] showed that lipid accumulation occurs in the glomerulus and proximal tubules in two animal models of glomerulonephritis (nephrotoxic serum nephritis and passive Heymann nephritis). In these models, lipid accumulation was associated with decreased SR-B1, increased ABCA1, and increased HMG CoA R levels, indicating that the normal adaptive response in the SR-B1-mediated influx and ABCA1-mediated efflux occurred with cellular cholesterol loading; however, increased synthesis contributed to increased cellular lipid accumulation. These data show that the intracellular lipid accumulation that follows injury can be crucial to cell survival; yet, when it persists in the face of chronic inflammatory stimuli, it becomes maladaptive and contributes to ongoing injury.

In addition to studies of animal models of glomerular injury [44], abnormal responses in specific kidney cells have been reported. Hypercholesterolemia and hypertriglyceridemia are associated with severe podocyte injury which secondarily leads to mesangial sclerosis [6]. Although these findings are striking, little is known about the specific effects of lipids on podocytes. The majority of work in the kidney has shown that mesangial cells (MC) metabolize lipids and respond to oxidized LDL in ways that are similar to those of VSMC (summarized in figure 1). MC express LDL receptors, SR-A and SR-B1, and CD36/SR-BII [18]. Ruan et al. [18] demonstrated dysregulation of the MC LDL receptor by a variety of inflammatory cytokines. Tumor necrosis factor alpha (TNF- $\alpha$ ) and interleukin 1 beta (IL-1 $\beta$ ) increased SREBP-1 which in turn increased the expression of the LDL receptor. This increase was no longer suppressed in a normal fashion by intracellular accumulation of cholesterol which has important implications for disease progression. Inflammatory cytokines, including IL-1 $\beta$, also induce intracellular accumulation of lipid by upregulating the expression of the type A SR that take up oxidized LDL. Cholesterol efflux by the PPAR-liver X receptor alpha-ABCA1 pathway is also impaired in IL-1 $\beta$-treated MC [27]. This could be reversed by PPAR- $\gamma$ agonists which protect MC from IL-1 $\beta$-induced intracellular lipid accumulation by activating the ABCA1 cholesterol efflux pathway. These observations have potential therapeutic implications. 
Activation of CD36 induces expression of chemokines and IL-6 which is a potent stimulus for mesangial sclerosis [45]. VLDL stimulates MC to express monocyte chemoattractant protein 1 [35]. In nephrotic syndrome, the lipids are primarily triglyceride rich, which may be relevant to new insights into foam cell formation, and recent data have shown that the majority of accumulated lipid in foam cells is triglyceride [34].

Similar to oxidized LDL, VLDL stimulates the expression of macrophage chemotactic protein 1 in MC [35]. Macrophage chemotactic protein 1, in turn, is chemotactic for macrophages which can infiltrate the glomerulus and become foam cells [46] that release cytokines and further modulate MC proliferation and matrix accumulation. Oxidized LDL induces MC to increase their expression of collagens I, III, and IV [47]. Also, MC express type A SR that are upregulated by angiotensin II [48]. This may in part explain why angiotensin-converting enzyme inhibitors slow the rate of fibrosis in kidney disease. LDL and minimally modified LDL are potent stimulants of MC proliferation [49]. In these ways, the glomerulus shares many features with other blood vessels in that it is susceptible to macrophage infiltration, foam cell conversion, and release of cytokines that contribute to perpetuate vascular injury.

\section{Insulin-Like Growth Factor 1 (IGF-1)/IGF-Binding Protein 5 (IGFBP-5) and Lipid Accumulation in MC}

We have been interested in the mechanisms whereby IGF-1 and IGFBP-5 modulate MC proliferation, migration, and cellular phenotype [50-52]. In studies comparing the effects of insulin and IGF-1, we found striking differences. IGF-1 induced MC to become elongated and grow in a swirling pattern as compared with the parallel, strap-like morphology associated with insulin. Furthermore, after 7 days of exposure to IGF-1, but not insulin, the MC became vacuolated. By electron microscopy, these $\mathrm{MC}$ resembled foam cells. Lipid accumulation was confirmed by staining with Nile red O [53]. The cellular uptake of cholesteryl ester was shown to be increased by treatment of cells with IGF-1. Although the mechanisms responsible for IGF-1-mediated lipid accumulation are unknown, endocytosis accounts for a significant portion of lipid that accumulates in macrophage foam cells [54]. In MC cholesteryl ester uptake correlated with enhanced rates of endocytosis which are known to be increased by IGF-1 [51]. Although IGF-1 induced foam cell formation in standard culture medium, this was greatly enhanced when the medium was supplemented with cholesteryl ester which emphasizes the role that high lipid levels play in accelerating disease, when IGF-1 or other inflammatory cytokines are present. The majority of work on the significance of foam cells in atherosclerosis has focused on the macrophage and its release of cytokines that alter the behavior of cells intrinsic to the vessel wall. Like MC, VSMC can become foam cells, yet, no studies have determined the functional consequences of this change. To explore that further, we examined several MC functions.

Shortly after exposure to IGF-1, there is a change in cytoskeleton and phenotype of MC [50]; however, after lipid accumulation has developed, the cytoskeleton becomes abnormally arrayed and no longer reorganizes in response to other stimuli such as IGFBP-5 [52]. To further characterize these changes, $\mathrm{MC}$ were lipid loaded by exposure to IGF-1 and then tested for their ability to engulf Escherichia coli. The MC adhered to E. coli, but the membrane was insufficiently mobile to completely encircle the bacterium and internalize it [51]. Because of the marked abnormalities in the cytoskeleton, we expected that other functions might also be impaired. In contrast to the usual synergistic migratory response that occurs when $\mathrm{MC}$ are exposed to both IGF-1 and IGFBP-5 short term, lipid-laden MC were unable to migrate in response to IGFBP-5 $[55,56]$. This effect was reversed when lipid was removed from the cells [52]. In addition to the abnormal migratory response, IGF1-induced MC foam cells did not contract in response to angiotensin II [52]. This effect was aggravated by the enhanced lipid accumulation that occurred, when the medium was supplemented with cholesteryl ester.

Abnormal contractile responses in the diabetic glomerulus might contribute to the increased intracapillary pressure and flows that have been demonstrated and postulated to contribute to injury [57]. These studies showing that IGF-1 drives foam cell formation are particularly relevant to disease, as rats transgenic for growth hormone or IGF-1 develop glomerulosclerosis [58], IGF-1 is increased in diabetic nephropathy [59], and IGF-1 contributes to VSMC proliferation in atherosclerotic plaques [60]. These are the first reports of alterations in function in smoothmuscle-like cells that express foam cell morphology.

\section{Role of Lipids in Renal Disease Progression}

There is growing evidence that abnormalities in lipid metabolism contribute to renal disease progression. At the same time, chronic kidney disease patients suffer from 
a secondary form of dyslipidemia that mimics the atherogenic dyslipidemia of insulin-resistant patients [61]. This is characterized by an increase in serum triglyceride (elevated VLDL remnants/intermediate-density lipoprotein), small dense LDL particles, and low HDL cholesterol. All of these particles are characterized by triglyceride-rich apolipoprotein-B-containing complex lipoproteins which have a significant atherogenic potential. Both preexisting and secondary dyslipidemia can contribute to the rate of progression of renal disease. Furthermore, the presence of microalbuminuria has been established as an independent risk factor for the development of cardiovascular morbidity and mortality $[62,63]$. This suggests that the pathogenic mechanisms responsible for cardiovascular and renal disease may be more similar than previously appreciated.

\section{Animal Data}

Studies in a variety of models in rats have shown that hypercholesterolemia accelerates the rate of progression of kidney disease. Also, high-cholesterol feeding leads to macrophage infiltration and foam cell formation in rats [46]. In a model of polycystic kidney disease, a high-fat diet accelerates disease which can be ameliorated by a diet rich in fish oils [64]. Because of the interaction between dyslipidemia and accelerated vascular disease in diabetes mellitus, a number of studies have focused on this interaction. Dominguez et al. [7] studied crosses of obesity-prone and spontaneously hypertensive rat models. Correlations were made between the degrees of glomerular, interstitial, and vascular injury with markers of glycoxidation and lipoxidation. The development of glomerulosclerosis and interstitial fibrosis was dependent on lipoxidation; without hypercholesterolemia, glycoxidation per se was not nephrotoxic. The specific role of lipids was further supported in a study of food restriction in Zucker rats [65]. Changes in protein excretion and progression best correlated with reductions in circulating lipids and were independent of leptin levels. Obese Zucker rats have significant glomerulosclerosis, and when hypertriglyceridemia is reduced, glomerular injury is reduced [4]. Further similarity to atherosclerosis and foam cell formation comes from studies showing that macrophage influx precedes glomerulosclerosis in Zucker rats [66]. In ovariectomized analbuminemic female rats, Joles et al. [6] were able to independently manipulate cholesterol and triglyceride levels. Both hypercholesterolemia and hypertriglyceridemia were associated with prominent podocyte injury, protein- uria, and interstitial injury, although mesangial changes were not prominent in that model. In nephrotic syndrome, there is a reduced clearance rather than an increased synthesis of VLDL which enhances interstitial injury. The creatinine clearance can be enhanced by fibrates [34]; thus, therapy might include agents that decrease VLDL, increase lipoprotein lipase activity, and correct HDL. In aggregate, these data indicate that abnormalities in the intracellular metabolism of lipids can contribute to renal injury independent of the initiating insult.

\section{Human Data}

Oxidized lipids [67] and foam cells [68] are prominent in some renal biopsy specimens from patients with renal disease, indicating analogies with atherosclerosis. Samuelsson et al. [69] demonstrated a strong correlation between triglyceride-rich, apolipoprotein-B-containing lipoproteins and the rate of progression in patients with chronic kidney disease. Patients with lecithin-cholesterol acyltransferase deficiency have glomerular lipid accumulation and eventually develop renal failure from glomerulosclerosis [70]. Possibly the best evidence for a relationship between lipids and progressive renal disease comes from studies of focal and segmental glomerulosclerosis and hyalinosis, where foam cells are prominent [71]. Lipid apheresis was reported to markedly reduce proteinuria in this disease [72]. In another study, LDL adsorption improved the response to corticosteroids in focal and segmental glomerulosclerosis [73]. Because of growing appreciation of the link between dyslipidemia, insulin resistance, and microalbuminuria and the risk of progressive renal disease [reviewed in 63], clinical trials are now examining the relationship between modification of lipid metabolism and renal protection. Oxidized LDL is immunogeneic. Atchley et al. [74] reported that circulating immune complexes of oxidized LDL-antioxidized LDL occur in diabetic individuals with proteinuria and nephropathy, suggesting that lipids may also contribute to renal disease progression through immune complex mediated injury.

\section{Concluding Remarks}

Under normal conditions, the intracellular content of cholesterol, fatty acids, and phospholipids is tightly regulated, as these lipids are essential to the structural integrity 
of the cell and its signal transduction cascades. Following acute cellular injury, cholesterol and triglyceride accumulate which may protect cells from additional injury. When inflammatory stimuli persist, lipid accumulation worsens, and foam cells develop which release cytokines that perpetuate lipid accumulation. This process is accelerated, when circulating lipid levels are elevated. In response to foam cell formation, MC fail to contract properly and secrete extracellular matrix that contributes to glomerulosclerosis. The significance of in vitro observations to disease is supported by animal and human studies which demonstrate the accumulation of foam cells in diseased kidneys [71]. Also, studies show that elevated levels of lipids accelerate disease progression which is improved by a variety of manipulations that lower circulating lipids or prevent intracellular lipid accumulation [75]. The complexity of this response to lipids provides challenge, as well as opportunities, for the development of therapeutic interventions that may modify the course of progressive kidney disease.

\section{Acknowledgements}

The studies reviewed herein from the author's laboratory were supported by the Medical Research Service of the Department of Veterans Affairs.

\section{References}

1 Scoble JE: Atherosclerotic nephropathy. Kidney Int Suppl 1999; 71:S106-S109.

2 Grone EF, Walli AK, Grone HJ, Miller B, Seidel D: The role of lipids in nephrosclerosis and glomerulosclerosis. Atherosclerosis 1994;107: $1-13$.

3 Keane WF, Kasiske BL, O’Donnell MP: Lipids and progressive glomerulosclerosis: A model analogous to atherosclerosis. Am J Nephrol 1988;8:261-271.

4 Kasiske BL, O'Donnell MD, Cleary MP, Keane WF: Treatment of hyperlipidemia reduces glomerular injury in obese Zucker rats. Kidney Int 1988;33:667-672.

5 Kees-Folts D, Diamond JR: Relationship between hyperlipidemia, lipid mediators, and progressive glomerulosclerosis in the nephrotic syndrome. Am J Nephrol 1993;13:365-375.

6 Joles JA, Kunter U, Janssen U, Kriz W, Rabelink TJ, Koomans HA, Floege J: Early mechanisms of renal injury in hypercholesterolemic or hypertriglyceridemic rats. J Am Soc Nephrol 2000;11:669-683.

7 Dominguez JH, Tang N, Xu W, Evan AP, Siakotos AN, Agarwal R, Walsh J, Deeg M, Pratt $\mathrm{JH}$, March KL, Monnier VM, Weiss MF, Baynes JW, Peterson R: Studies of renal injury. III. Lipid-induced nephropathy in type II diabetes. Kidney Int 2000;57:92-104

8 Heinecke JW, Suits AG, Aviram M, Chait A: Phagocytosis of lipase-aggregated low-density lipoprotein promotes macrophage foam cell formation: Sequential morphological and biochemical events. Arterioscler Thromb 1991;11: 1643-1651.

9 Chait A, Heinecke JW: Lipoprotein modification: Cellular mechanisms. Curr Opin Lipidol 1994;5:363-370.

10 de Winther MP, Hofker MH: Scavenging new insights into atherogenesis. J Clin Invest 2000; 105:1039-1041.

11 Li H, Freeman MW, Libby P: Regulation of smooth muscle cell scavenger receptor expression in vivo by atherogenic diets and in vitro by cytokines. J Clin Invest 1995;95:122-133.
12 Bayes-Genis A, Conover CA, Schwartz RS: The insulin-like growth factor axis: A review of atherosclerosis and restenosis. Circ Res 2000; 86:125-130.

13 Wheeler DC, Chana RS: Interactions between lipoproteins, glomerular cells and matrix. Miner Electrolyte Metab 1993;19:149-164.

14 Chait A, Brazg RL, Tribble DL, Krauss RM: Susceptibility of small, dense, low-density lipoproteins to oxidative modification in subjects with the atherogenic lipoprotein phenotype, pattern B. Am J Med 1993;94:350-356.

15 Ribalta J, Vallve JC, Girona J, Masana L: Apolipoprotein and apolipoprotein receptor genes, blood lipids and disease. Curr Opin Clin Nutr Metab Care 2003;6:177-187.

16 Kwiterovich PO Jr.: Clinical relevance of the biochemical, metabolic, and genetic factors that influence low-density lipoprotein heterogeneity. Am J Cardiol 2002;90:30i-47i.

17 Sun L, Halaihel N, Zhang W, Rogers T, Levi $\mathrm{M}$ : Role of sterol regulatory element-binding protein 1 in regulation of renal lipid metabolism and glomerulosclerosis in diabetes mellitus. J Biol Chem 2002;277:18919-18927.

18 Ruan XZ, Varghese Z, Powis SH, Moorhead JF: Dysregulation of LDL receptor under the influence of inflammatory cytokines: A new pathway for foam cell formation. Kidney Int 2001;60:1716-1725.

19 Hussain MM, Strickland DK, Bakillah A: The mammalian low-density lipoprotein receptor family. Annu Rev Nutr 1999;19:141-172.

20 Podrez EA, Febbraio M, Sheibani N, Schmitt D, Silverstein RL, Hajjar DP, Cohen PA, Frazier WA, Hoff HF, Hazen SL: Macrophage scavenger receptor $\mathrm{CD} 36$ is the major receptor for LDL modified by monocyte-generated reactive nitrogen species. J Clin Invest 2000;105: 1095-1108.

21 Li AC, Glass CK: The macrophage foam cell as a target for therapeutic intervention. Nat Med 2002;8:1236-1242.
22 Han J, Hajjar DP, Tauras JM, Nicholson AC: Cellular cholesterol regulates expression of the macrophage type B scavenger receptor, CD36. J Lipid Res 1999;40:830-838.

23 Draude G, Lorenz RL: TGF-betal downregulates CD36 and scavenger receptor A but upregulates LOX-1 in human macrophages. Am J Physiol 2000;278:H1042-H1048.

24 Rothblat GH, de la Llera-Moya M, Atger V, Kellner-Weibel G, Williams DL, Phillips MC: Cell cholesterol efflux: Integration of old and new observations provides new insights. J Lipid Res 1999;40:781-796.

25 Schmitz G, Büchler C: ABCA1: Regulation, trafficking and association with heterotrimeric proteins. Ann Med 2002;34:334-347.

26 Chawla A, Repa JJ, Evans RM, Mangelsdorf DJ: Nuclear receptors and lipid physiology: Opening the X-files. Science 2001;294:18661870.

27 Ruan XZ, Moorhead JF, Fernando R, Wheeler DC, Powis SH, Varghese Z: PPAR antagonists protect mesangial cells from interleukin $1 \beta$ induced intracellular lipid accumulation by activating the ABCA1 cholesterol efflux pathway. J Am Soc Nephrol 2003; 14:593-600.

28 Han J, Hajjar DP, Zhou X, Gotto AM Jr, Nicholson AC: Regulation of peroxisome proliferator-activated receptor- $\gamma$-mediated gene expression: A new mechanism of action for high-density lipoprotein. J Biol Chem 2002; 277:23582-23586.

29 Tabata T, Mine S, Kawahara C, Okada Y, Tanaka Y: Monocyte chemoattractant protein1 induces scavenger receptor expression and monocyte differentiation into foam cells. Biochem Biophys Res Commun 2003;305:380 385.

30 Febbraio M, Hajjar DP, Silverstein RL: CD36: A class B scavenger receptor involved in angiogenesis, atherosclerosis, inflammation, and lipid metabolism. J Clin Invest 2001;108:785791. 
31 Febbraio M, Podrez EA, Smith JD, Hajjar DP, Hazen SL, Hoff HF, Sharma K, Silverstein RL: Targeted disruption of the class B scavenger receptor $\mathrm{CD} 36$ protects against atherosclerotic lesion development in mice. J Clin Invest 2000; 105:1049-1056.

32 Pravenec M, Kurtz TW: Genetics of CD36 and the hypertension metabolic syndrome. Semin Nephrol 2002;22:148-153.

33 Glazier AM, Scott J, Aitman TJ: Molecular basis of the $\mathrm{Cd} 36$ chromosomal deletion underlying SHR defects in insulin action and fatty acid metabolism. Mamm Genome 2002;13: 108-113.

34 O'Donnell MP: Mechanisms and clinical importance of hypertriglyceridemia in the nephrotic syndrome. Kidney Int 2001;59:380382.

35 Lynn EG, Siow YL, O K: Very low-density lipoprotein stimulates the expression of monocyte chemoattractant protein-1 in mesangial cells. Kidney Int 2000;57:1472-1483.

36 Chisolm GM: Cytotoxicity of oxidized lipoproteins. Curr Opin Lipidol 1991;2:311-316.

37 de Villiers WJ, Smart EJ: Macrophage scavenger receptors and foam cell formation. J Leukoc Biol 1999;66:740-746.

38 Brewer HB Jr: The lipid-laden foam cell: An elusive target for therapeutic intervention. $\mathrm{J}$ Clin Invest 2000;105:703-705.

39 Milosavljevic D, Kontush A, Griglio S, Le Naour G, Thillet J, Chapman MJ: VLDLinduced triglyceride accumulation in human macrophages is mediated by modulation of LPL lipolytic activity in the absence of change in LPL mass. Biochim Biophys Acta 2003; 1631:51-60.

40 Studer RK, Negrete H, Craven PA, DeRubertis FR: Protein kinase $\mathrm{C}$ signals thromboxaneinduced increases in fibronectin synthesis and TGF- $\beta$ bioactivity in mesangial cells. Kidney Int 1995;48:422-430.

41 Zager RA, Johnson A, Anderson K, Wright S Cholesterol ester accumulation: An immediate consequence of acute in vivo ischemic renal injury. Kidney Int 2001;59:1750-1761.

42 Zager RA, Johnson A: Renal cortical cholesterol accumulation is an integral component of the systemic stress response. Kidney Int 2001; 60:2299-2310.

43 Zager RA, Johnson A, Hanson S, dela Rosa V: Altered cholesterol localization and caveolin expression during the evolution of acute renal failure. Kidney Int 2002;61:1674-1683.

44 Johnson AC, Yabu JM, Hanson S, Shah VO, Zager RA: Experimental glomerulopathy alters renal cortical cholesterol, SR-B1, ABCA1, and HMG CoA reductase expression. Am J Pathol 2003;162:283-291.

45 Massy ZA, Kim Y, Guijarro C, Kasiske B, Keane WF, O’Donnell MP: Low-density lipoprotein-induced expression of interleukin-6, a marker of human mesangial cell inflammation: Effects of oxidation and modulation by lovastatin. Biochem Biophys Res Commun 2000; 267:536-540.
46 Hattori M, Nikolic-Paterson DJ, Miyazaki K, Isbel NM, Lan HY, Atkin RC, Kawaguchi H, Ito K: Mechanisms of glomerular macrophage infiltration in lipid-induced renal injury. Kidney Int Suppl 1999;71:S47-S50.

47 Lee HS, Kim BC, Hong HK, Kim YS: LDL stimulates collagen mRNA synthesis in mesangial cells through induction of PKC and TGFbeta expression. Am J Physiol 1999;277:F369_ F376.

48 Ruan XZ, Varghese Z, Powis SH, Moorhead JF: Human mesangial cells express inducible macrophage scavenger receptor. Kidney Int 1999;56:440-451.

49 Kamanna VS, Bassa BV, Vaziri ND, Roh DD: Atherogenic lipoproteins and tyrosine kinase mitogenic signaling in mesangial cells. Kidney Int Suppl 1999;71:S70-S75.

50 Berfield AK, Spicer D, Abrass CK: Insulin-like growth factor I (IGF-I) induces unique effects in the cytoskeleton of cultured rat glomerular mesangial cells. J Histochem Cytochem 1997; 45:583-593

51 Berfield AK, Abrass CK: IGF-1 induces foam cell formation in rat glomerular mesangial cells. J Histochem Cytochem 2002;50:395403.

52 Berfield AK, Andress DL, Abrass CK: IGF-1induced lipid accumulation impairs mesangial cell migration and contractile function. Kidney Int 2002;62:1229-1237.

53 Fowler SD, Greenspan P: Applications of Nile red, a fluorescent hydrophobic probe, for the detection of neutral lipid deposits in tissue sections. J Histochem Cytochem 1985;33:833836.

54 Kruth HS, Huang W, Ishii I, Zhang WY: Macrophage foam cell formation with native low density lipoprotein. J Biol Chem 2002;277: 34573-34580.

55 Abrass CK, Berfield AK, Andress DL: Heparin binding domain of insulin-like growth factor binding protein-5 stimulates mesangial cell migration. Am J Physiol 1997;273:F899-F906.

56 Berfield AK, Andress DL, Abrass CK: IGFBP5201-218 stimulates Cdc42 aggregation and filopodia formation in migrating mesangial cells. Kidney Int 2000;57:1991-2003.

57 Hostetter TH, Rennke HG, Brenner BM: The case for intrarenal hypertension in the initiation and progression of diabetic and other glomerulopathies. Am J Med 1982;72:375380 .

58 Doi T, Striker LJ, Gibson CC, Agodoa LY, Brinster RL, Striker GE: Glomerular lesions in mice transgenic for growth hormone and insulinlike growth factor-I. I. Relationship between increased glomerular size and mesangial sclerosis. Am J Pathol 1990;137:541-552.

59 Elliot SJ, Striker LJ, Hattori M, Yang CW, He CJ, Peten EP, Striker GE: Mesangial cells from diabetic NOD mice constitutively secrete increased amounts of insulin-like growth factor-I. Endocrinology 1993;133:1783-1788.
60 Frystyk J, Ledet T, Møller N, Flyvberg A, Ørskov H: Cardiovascular disease and insulinlike growth factor I. Circulation 2002;106:893895.

61 Wanner C, Krane V: Uremia-specific alterations in lipid metabolism. Blood Purif 2002;20: 451-453.

62 Weinstock Brown W, Keane WF: Proteinuria and cardiovascular disease. Am J Kidney Dis 2001;38(4 Suppl 1):S8-S13.

63 Keane WF: The role of lipids in renal disease: Future challenges. Kidney Int 2003;57:S27S31.

64 Lu J, Bankovic-Calic N, Ogborn M, Saboorian MH, Aukema HM: Detrimental effects of a high fat diet in early renal injury are ameliorated by fish oil in Han:SPRD-cy rats. J Nutr 2003; 133:180-186.

65 Maddox DA, Alavi FK, Santella RN, Zawata ET Jr.: Prevention of obesity-linked renal disease: Age-dependent effects of dietary food restriction. Kidney Int 2002;62:208-219.

66 Lavaud S, Michel O, Sassy-Prigent C, Heudes D, Bazin R, Bari'ety J, Chevalier J: Early influx of glomerular macrophages precedes glomerulosclerosis in the obese Zucker rat model. J Am Soc Nephrol 1996;7:2604-2615.

67 Lee HS, Kim YS: Identification of oxidized low density lipoproteins in human renal biopsies. Kidney Int 1998;54:848-856.

68 Magil AB: Interstitial foam cells and oxidized lipoprotein in human glomerular disease. Mod Pathol 1999;12:33-40.

69 Samuelsson O, Mulec H, Knight-Gibson C, Attman PO, Kron B, Larsson R, Weiss L, Wedel H, Alaupovic P: Lipoprotein abnormalities are associated with increased rate of progression of human chronic renal insufficiency. Nephrol Dial Transplant 1997;12:1908-1915.

70 Lambert G, Sakai N, Vaisman BL, Neufeld EB, Marteyn B, Chan CC, Paigen B, Lupia E, Thomas A, Striker LJ, Blanchette-Mackie J, Csako G, Brady JN, Costello R, Striker GE, Remaley AT, Brewer HB Jr, Santamarina-Fojo S: Analysis of glomerulosclerosis in lecithin cholesterol acyltransferase-deficient mice. J Biol Chem 2001;276:15090-15098.

71 Noel LH: Morphological features of primary focal and segmental glomerulosclerosis. Nephrol Dial Transplant 1999;14(Suppl 3):5357.

72 Yorioka N, Taniguchi Y, Nishida Y, Okushin S, Amimoto D, Yamakido A: Low-density lipoprotein apheresis for focal glomerular sclerosis. Ther Apher 1997;1:370-371.

73 Yokoyama K, Sakai S, Sigematsu T, Takemoto F, Hara S, Yamada A, Kawaguchi Y, Hosoya $\mathrm{T}$ : LDL adsorption improves the response of focal glomerulosclerosis to corticosteroid therapy. Clin Nephrol 1998;50:1-7.

74 Atchley DH, Lopes-Virella MF, Zheng D, Kenny D, Virella G: Oxidized LDL-antioxidized LDL immune complexes and diabetic nephropathy. Diabetologia 2002;45:1562-1571.

75 Oda H, Keane WF: Recent advances in statins and the kidney. Kidney Int Suppl 1999;71:S2S5 